\title{
Bone marrow-derived mesenchymal stem cells promote colorectal cancer progression via CCR5
}

\author{
Gen Nishikawa', Kenji Kawada', Jun Nakagawa', Kosuke Toda', Ryotaro Ogawa', Susumu Inamoto', Rei Mizuno', \\ Yoshiro Itatani $^{1}$ and Yoshiharu Sakai ${ }^{1}$
}

\begin{abstract}
Mesenchymal stem cells (MSCs) are recruited from BM to the stroma of developing tumors, where they serve as critical components of the tumor microenvironment by secreting growth factors, cytokines, and chemokines. The role of MSCs in colorectal cancer (CRC) progression was controversial. In this study, we found that C-C chemokine receptor type 5 (CCR5) ligands (i.e., C-C motif chemokine ligand 3 (CCL3), CCL4, and CCL5) were highly produced from MSCs using a chemokine array screening with conditioned media from the cultured human MSCs. A relatively strong CCR5 expression could be detected within the cytoplasm of several CRC cell lines. Regarding the effect of MSC, we found that the xenografts in which CCR5-overexpressing HCT116 cells were inoculated into immunocompromised mice were highly promoted in vivo by a mixture with MSCs. Notably, the CCR5 inhibitor, maraviroc, significantly abolished the MSC-induced tumor growth in vivo. In human clinical specimens $(n=89), 20$ cases $(29 \%)$ were high for CCR5, whereas 69 cases (71\%) were low. Statistical analyses indicated that CCR5 expression in primary CRC was associated with CRC patients' prognosis. Especially, stage III/IV patients with CCR5-high CRCs exhibited a significantly poorer prognosis than those with CCR5-low CRCs. Furthermore, we investigated the effects of preoperative serum CCR5 ligands on patients' prognosis $(n=114)$, and found that CRC patients with high serum levels of CCL3 and CCL4 exhibited a poorer prognosis compared to those with low levels of CCL3 and CCL4, while there was no association between CCL5 and prognosis. These results suggest that the inhibition of MSC-CRC interaction by a CCR5 inhibitor could provide the possibility of a novel therapeutic strategy for CRC, and that serum levels of CCL3 and CCL4 could be predictive biomarkers for the prognosis of CRC patients.
\end{abstract}

\section{Introduction}

Colorectal cancer $(\mathrm{CRC})$ is the third most common cancer and the fourth most common cause of cancer death worldwide, accounting for about 1.36 million deaths every year ${ }^{1}$. If it remains localized, the 5 -year survival rate is about $90 \%$. When it spreads to lymph nodes and distant organs, the 5 -year survival rate reduces to about $70 \%$ and to about $10 \%$, respectively ${ }^{2}$. There is mounting evidence that the tumor-stromal interaction, so-called tumor

Correspondence: Kenji Kawada (kkawada@kuhp.kyoto-u.ac.jp)

'Department of Surgery, Graduate School of Medicine, Kyoto University, Kyoto, Japan

Edited by M. Agostini microenvironment (TME), promotes tumor invasion and metastasis through chemokine signaling ${ }^{3}$. The tumor stroma contains extracellular matrix and several types of host cells, including immune cells, vascular cells, and mesenchymal cells. The molecular mechanisms involved in the recruitment of these stromal cells to the tumor are poorly understood.

Mesenchymal stem cells (MSCs) were first discovered in bone marrow (BM) stroma in the $1960 \mathrm{~s}^{4}$, and are pluripotent progenitor cells that contribute to the normal homeostasis and remodeling following injury in a variety of tissues ${ }^{5}$. Although MSCs reside predominantly in the $\mathrm{BM}$, they can be distributed throughout the body. MSCs

\section{(c) The Author(s) 2019}

(c) (i) Open Access This article is licensed under a Creative Commons Attribution 4.0 International License, which permits use, sharing, adaptation, distribution and reproduction c. in any medium or format, as long as you give appropriate credit to the original author(s) and the source, provide a link to the Creative Commons license, and indicate if changes were made. The images or other third party material in this article are included in the article's Creative Commons license, unless indicated otherwise in a credit line to the material. If material is not included in the article's Creative Commons license and your intended use is not permitted by statutory regulation or exceeds the permitted use, you will need to obtain permission directly from the copyright holder. To view a copy of this license, visit http://creativecommons.org/licenses/by/4.0/. 
display some properties, such as the tendency to home into the sites of injury, capacity to suppress immune reactions, and promote the repair of damaged tissues. Due to these properties, MSCs have been explored for their application as cell sources in regenerative medicine and as delivery vehicles in gene therapy ${ }^{5}$. Growing tumors are considered as "chronic wounds that do not heal" , and can activate the recruitment of host cells to promote proliferation and survival of tumor cells. In the context of cancer, recent studies have proposed that MSCs are recruited from BM to the stroma of developing tumors, where they serve as critical components of the TME. For example, Karnoub et al. reported that when breast cancer cells were mixed with MSCs and injected subcutaneously, lung metastasis was accelerated through the CCL5-CCR5 axis in the experimental mouse models ${ }^{7}$. Some chemokines and cytokines have been reported to be involved in the interaction between MSCs and cancers ${ }^{8,9}$.

In the present study, we investigated the interaction between CRC cells and MSCs, focusing on the chemokine signaling. We demonstrated that human MSCs secreted high levels of CCR5 ligands (i.e., CCL3, CCL4, and CCL5), and that MSCs promoted CRC tumor growth in vivo via CCR5 signaling. The xenografts in which CCR5overexpressing CRC cells were inoculated into immunocompromised mice were highly promoted by a mixture with MSCs. Notably, we found that the CCR5 inhibitor, maraviroc, abolished the MSC-induced tumor growth in vivo. In human clinical specimens, we found that CCR5 expression in primary CRC was associated with CRC patients' prognosis. Especially, stage III/IV patients with CCR5-high CRCs exhibited a significantly poorer prognosis than those with CCR5-low CRCs. We further showed that CRC patients with high serum levels of CCL3 and CCL4 exhibited a poorer prognosis compared to those with low levels of CCL3 and CCL4. These results suggest that a CCR5 inhibitor may provide the possibility of a novel therapeutic strategy for CRC, and that serum levels of CCL3 and CCL4 could be predictive biomarkers for the prognosis of CRC patients.

\section{Results}

CCL3/4/5-CCR5 axis is a candidate that functions between MSCs and CRC cells, which resulted in tumor growth in vivo

Based on the previous reports that have shown that MSCs promote tumor progression in several types of cancer including breast cancer ${ }^{7,10}$, prostate cancer ${ }^{11,12}$, and gastric cancer ${ }^{13-15}$, we hypothesized that the chemokine crosstalk between MSCs and tumor cells played a role in the CRC microenvironment. To explore a candidate that functions between MSCs and CRC cells, conditioned media from the cultured human MSCs were screened for various chemokines using a chemokine array kit. Of note, several chemokines were produced by MSCs at a relatively high level, and, especially, CCL3, CCL4, and CCL5 were highly detected (Fig. 1a). We also confirmed the expressions of these chemokines at mRNA levels by quantitative reverse transcription-PCR (qRT-PCR; data not shown). Because the cognate receptor for these chemokines is CCR5, we speculated that CCL3/4/5-CCR5 axis could function between MSCs and CRC cells.

Next, we examined the expression of CCR5 in several CRC cell lines by flow cytometry, and found that these cells slightly expressed CCR5 on the cell surface (Fig. 1b, top). However, when cell membrane was permeabilized, a relatively strong CCR5 expression could be detected within the cytoplasm (Fig. 1b, bottom).

To investigate the functional consequences of the interaction between MSCs and CRC cells, we employed the co-inoculation mice model in which CRC cells $(1 \times$ $10^{6}$ cells) were mixed with BM-derived human MSCs $(1 \times$ $10^{6}$ cells) and injected subcutaneously into immunocompromised mice (Fig. 1c). The growth kinetics of the MSC-mixed tumors (CRC cells + MSCs) in mice were compared to those injected with CRC cells alone. We tested three CRC cell lines (i.e., HT29, SW480, and HCT116), and found that the mixture of MSCs significantly accelerated tumor growth in vivo in all cell lines (Fig. 1d). Mice injected with HT29 + MSCs displayed the significantly larger tumors compared to those injected with HT29 alone. Mice injected with SW480 + MSCs or HCT116 + MSCs displayed the visible tumors, whereas mice injected with SW480 or HCT116 alone did not exhibit tumor engraftment.

\section{CCR5-mediated cellular responses of CRC cell lines}

To investigate the role of CCR5 in CRC progression, we established stable HCT116 transfected lines in which CCR5 or empty vector was introduced by retroviral transfection (referred as HCT116-CCR5 or HCT116-EV cells, respectively). We confirmed that the mRNA and protein levels of CCR5 were markedly higher in HCT116CCR5 cells compared to the control cells (HCT116-EV cells) (Fig. 2a, b). To examine the intracellular signaling pathways via CCR5, we analyzed the phosphorylation of Erk, PI3K, and Akt after treatment with CCL5 (Fig. 2c). Upon exposure of HCT116-CCR5 cells to CCL5, there was notable phosphorylation of Erk, PI3K, and Akt. On the other hand, in HCT116-EV cells, CCL5 stimulation caused only the phosphorylation of PI3K, while it did not increase the phosphorylation of Erk and Akt. Next, to explore the CCR5-mediated cellular function, we analyzed the effect of CCL5 on cell proliferation, and found that CCL5 significantly enhanced the proliferation of both HCT116-EV and HCT116-CCR5 cells (Fig. 2d). The proliferation rates of HCT116-CCR5 cells with or without CCL5 were almost similar to those of HCT116-EV cells, indicating the overexpressed CCR5 did not confer any 


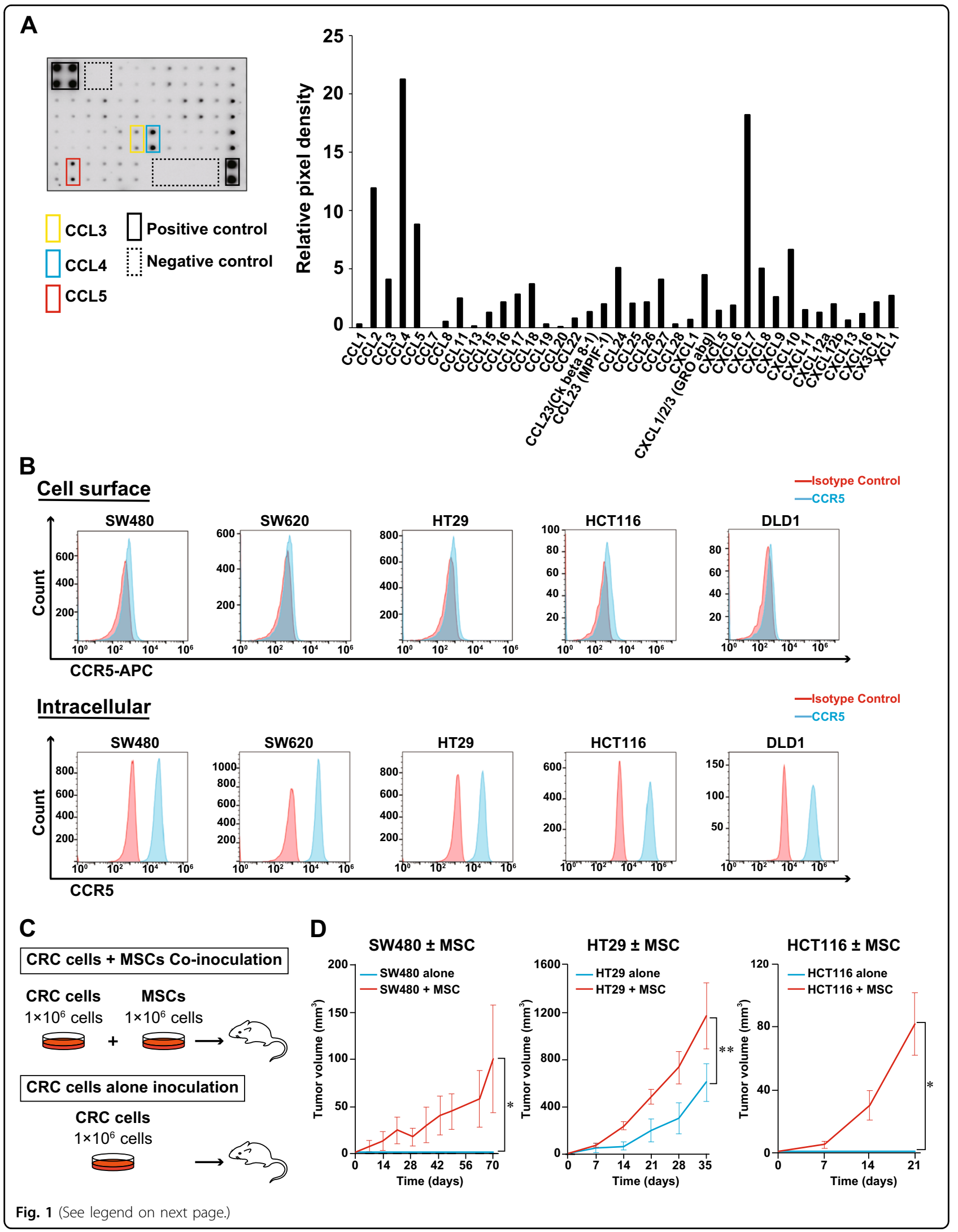


(see figure on previous page)

Fig. 1 Relationship between colorectal cancer (CRC) cells and mesenchymal stem cells (MSCs). a Chemokine array using supernatants collected from MSCs. Array membrane (left) and relative intensity values of each chemokine (right). A positive control was set as 100 . b Cell surface expression (top) and intracellular expression (bottom) of C-C chemokine receptor type 5 (CCR5) analyzed by flow cytometry. Red area represented isotype lgG control and blue area did anti-CCR5 Ab. c Schema of co-inoculation mice model. $\mathbf{d}$ Xenograft growth curves of SW480 (letf), HT29 (middle), and HCT116 (ritght) injected with or without MSCs. Mean; bar, \pm SE, $n=4$ (SW480), $n=6$ (HT29 and HCT116) (Student's $t$ test; * $P<0.01$, $\left.{ }^{*} P=0.03\right)$

proliferative advantage. Furthermore, we performed an in vitro chemotaxis assay to investigate whether the chemokine axis via CCR5 could induce cell migration. As expected, CCL5 caused directional migration in HCT116CCR5 cells, whereas it did not in HCT116-EV cells (Fig. 2e).

\section{MSC promotes CRC tumor growth in vivo via CCR5}

To assess the effect of CCR5 on the tumor growth in vivo, we inoculated HCT116-EV or HCT116-CCR5 cells $\left(4 \times 10^{6}\right.$ cells $)$ into immunocompromised mice and found that there was no significant difference in size between the two cells (Supplementary Fig. 1). Next, to examine the effect of MSC mixture, we employed the coinoculation mice model in which HCT116-EV or HCT116-CCR5 cells $\left(1 \times 10^{6}\right.$ cells $)$ were mixed with MSCs $\left(1 \times 10^{6}\right.$ cells $)$, and then inoculated subcutaneously into the mice (Fig. 3a). The size of the tumors in mice injected with HCT116-CCR5 + MSCs was much larger compared to that in mice injected with HCT116-EV+ MSCs (Fig. 3b, c). Three weeks after inoculations, we confirmed that CCR5 protein continued to be expressed in the HCT116-CCR5 + MSCs tumors, and that the pathological findings of the transplanted tumors were similar between the two cells (Fig. 3c). There were a few alpha-smooth muscle actin ( $\alpha$-SMA)-positive cells within these tumors.

To additionally verify the roles of CCR5, we attempted to suppress tumor growth with a CCR5 inhibitor, maraviroc. Seven days after inoculation, we started to inject maraviroc $(30 \mathrm{mg} / \mathrm{kg} /$ day) repeatedly into the mice, and then compared the effect to the control vehicle up to 3 weeks after inoculation. In the HCT116-EV + MSCs tumors, there was no significant difference in size between the two groups $(P=0.37)$. On the other hand, in the HCT116-CCR5 + MSCs tumors, maraviroc significantly reduced tumor size $(P=0.042)$. These results suggest that CCR5 signaling is important for the interaction between CRC cells and MSCs, and that an inhibitor of CCR5 could suppress CRC progression.

CCR5 expression in primary CRC and preoperative serum CCL3/4 levels are correlated with patients' prognosis

To evaluate the clinical relevance of the abovementioned results, we examined CCR5 expression in CRC cells with 89 clinical specimens by immunohistochemical analysis. We found that 20 cases $(20 / 89 ; 29 \%)$ had high levels of CCR5, whereas 69 cases $(69 / 89 ; 71 \%)$ had comparatively lower levels (Fig. 4a). CCR5 expression was not associated with sex, age, tumor location, T-factor, Nfactor, and M-factor (Table 1). To evaluate the effect of patients' prognosis, we analyzed the overall survival (OS), cancer-specific survival (CSS), and relapse-free survival (RFS). Statistical analyses indicated that stages 0-IV patients with CCR5-high CRCs tended to exhibit shorter OS and CSS than those with CCR5-low CRCs $(P=0.08$ and 0.07 , respectively), although the difference was not significant (Fig. 4b). Furthermore, we performed subgroup analyses based on the stage-based classification, and found that stage III/IV patients with CCR5-high CRCs exhibited a significantly poorer prognosis (OS, CSS, and RFS) than those with CCR5-low CRCs $(P=0.001,0.009$, and 0.035 , respectively; Fig. 4c). On the other hand, such a correlation was not observed in the analyses on stage $0 / \mathrm{I} /$ II patients. These results highlight the clinical importance of CCR5 expression in CRC, especially at advanced stages.

Serum levels of CCL3, CCL4, and CCL5 have been recently reported to be useful as biomarkers of several cancers $^{16-21}$. Therefore, we investigated whether they could be used as biomarkers of CRC progression. We measured the preoperative serum levels of CCL3, CCL4, and CCL5 from 114 CRC patients by enzyme-linked immunosorbent assay (ELISA) (Table 2). To evaluate the clinical outcome, we analyzed the OS, CSS, and RFS. Statistical analysis indicated that the cases with high CCL3 levels exhibited a significantly shorter OS and CSS compared to those with low CCL3 levels $(P=0.02$ and 0.02 , respectively), although such a correlation was not observed in RFS (Fig. 5a). The cases with high CCL4 levels exhibited a significantly shorter OS compared to those with low CCL4 levels $(P=0.04)$, and a similar correlation was also observed in CSS and RFS $(P=0.06$ and 0.07 , respectively) (Fig. $5 \mathrm{~b}$ ). On the other hand, there was no association between the CCL5 concentration and prognosis (Fig. 5c).

\section{Discussion}

MSCs have the multilineage differentiation potential and the capacity to home into the damaged tissues and modulate immune responses. Because of these properties, 

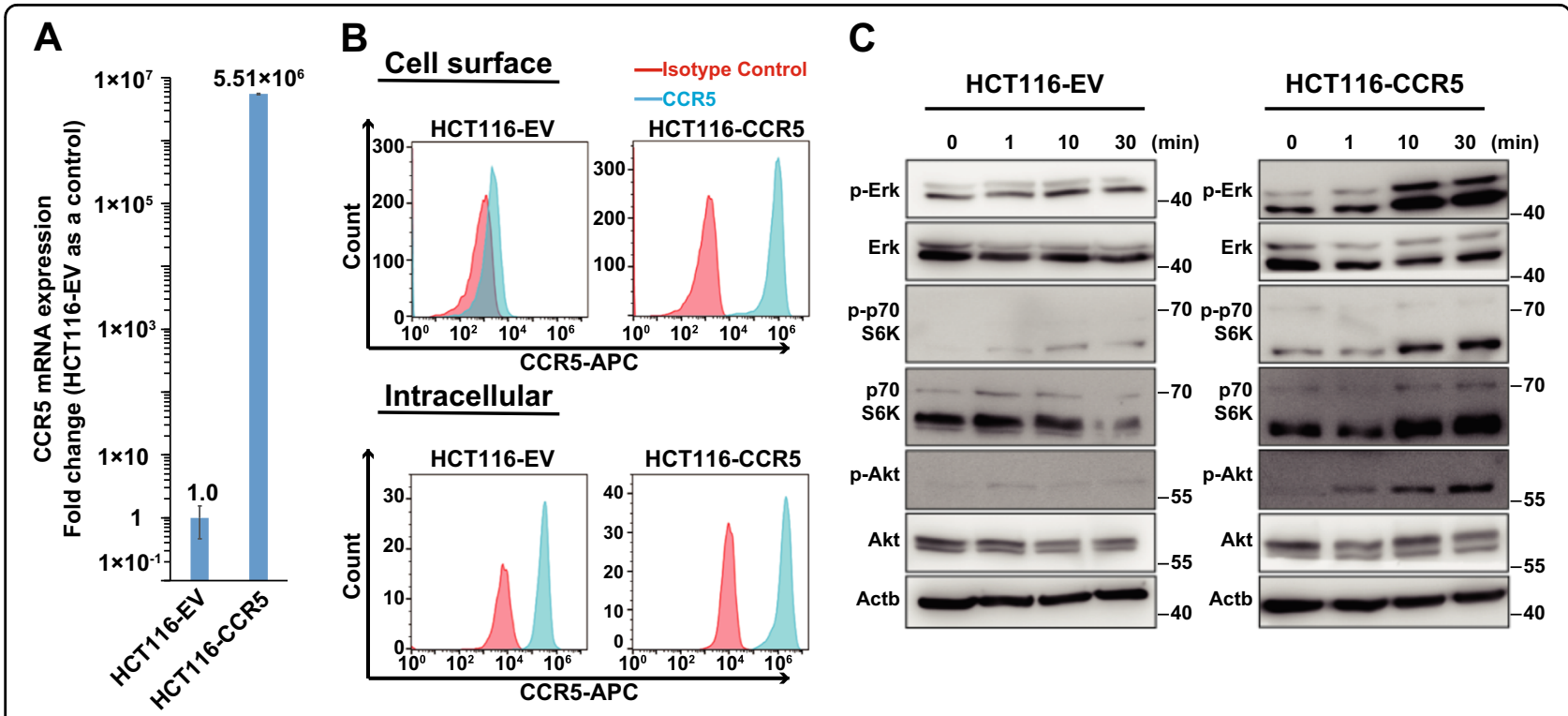

D
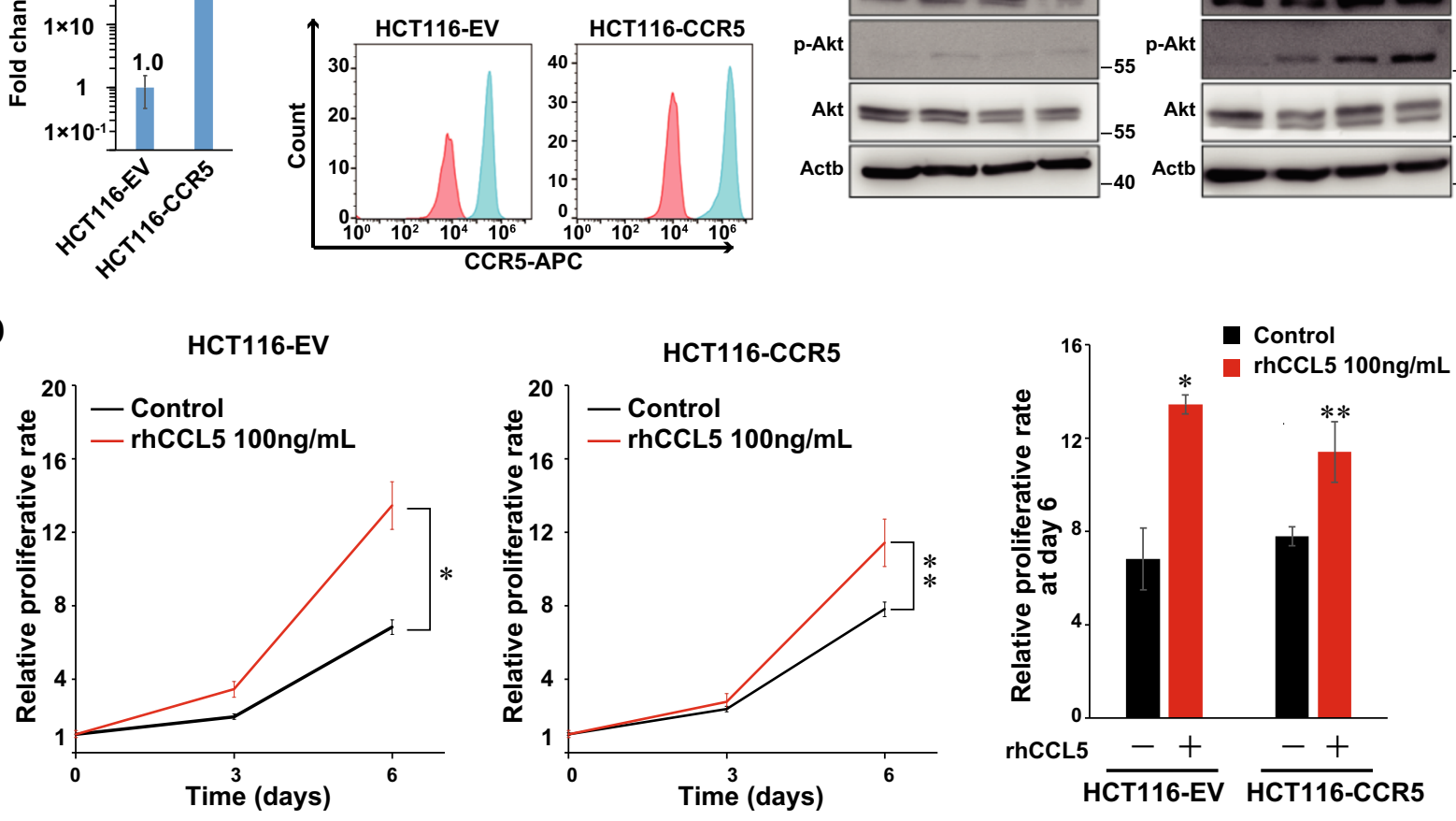

E
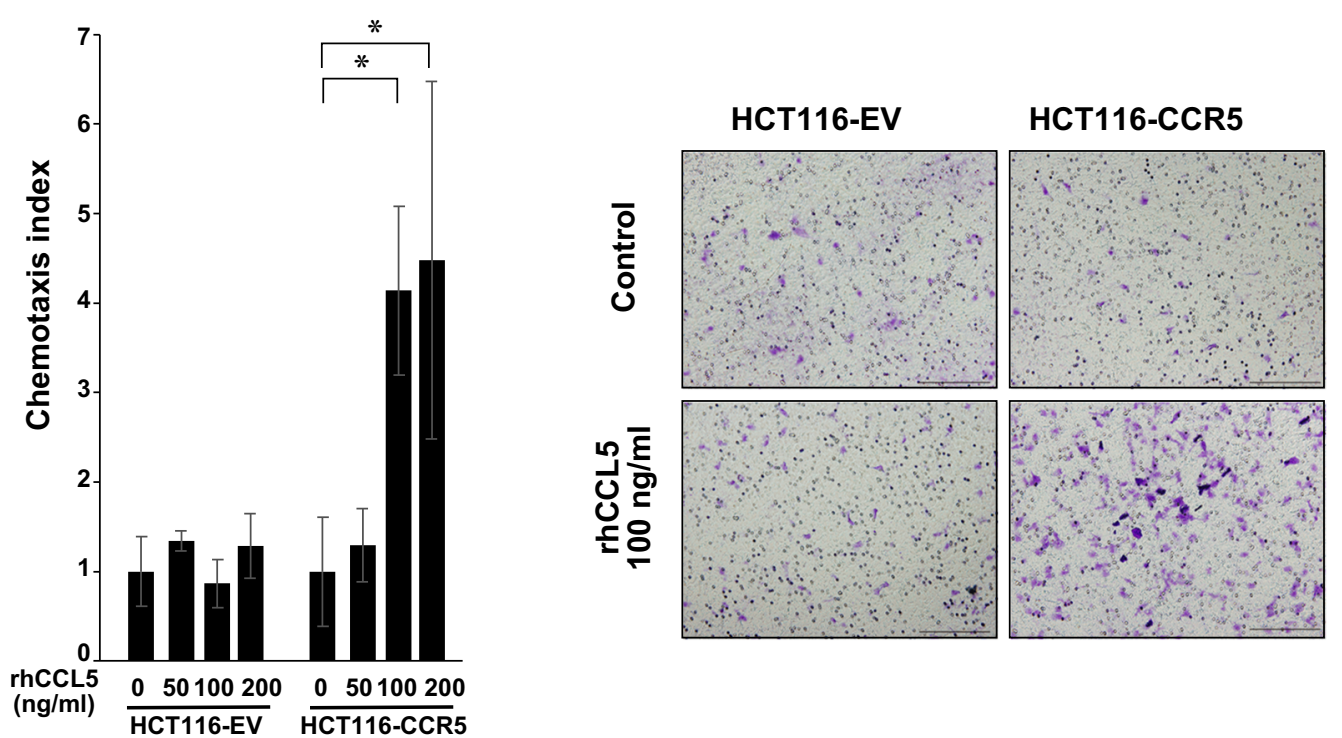

Fig. 2 (See legend on next page.) 
(see figure on previous page)

Fig. 2 C-C chemokine receptor type $\mathbf{5}$ (CCR5)-mediated cellular responses in vitro. a CCR5 mRNA expression in HCT116 transfectant cells quantified by quantitative reverse transcription-PCR. Means; bar, $\pm \mathrm{SD}, n=3$. b CCR5 cell surface expression (top) and intracellular expression (bottom) analyzed by flow cytometry. $\mathbf{c}$ Intracellular signaling of HCT116 transfectant cells treated with C-C motif chemokine ligand 5 (CCL5; $100 \mathrm{ng} / \mathrm{ml})$. d Cell proliferation assay using Cell Counting Kit-8 assay. HCT116 transfectant cells treated with CCL5 (100 ng/ml) analyzed at day 0, 3, and 6. Normalize an absorbance at day 0 as 1 . Mean; bars, $\pm \mathrm{SD}, n=3$ (Student's $t$ test; ${ }^{*} P=0.008,{ }^{*} P=0.03$ ). e Chemotaxis index of HCT1 16 transfectant cells treated with various CCL5 concentrations (left). Mean; bars, \pm SD, $n=6$ (Student's $t$ test; ${ }^{*} P<0.001$ ). Representative images of transwell membrane (right). Scale bar, $200 \mu \mathrm{m}$

the therapeutic value of MSCs has been investigated in various diseases including regenerative medicine $e^{5,22,23}$. However, some studies have reported the risk of potential tumorigenicity related to the MSC-based therapy through genetic instability and transformation after prolonged cell culture $^{23-25}$. Although there are not enough data/studies to draw a conclusion about the risk of tumorigenicity in the MSC-based therapy, the development of long-term follow-up in clinical settings is encouraged. Tumorpromoting effect of MSCs have been reported in various types of cancer, including $\mathrm{CRC}^{26-30}$. Recently, Chen et al. reported that CCL 5 secreted by tumor necrosis factor- $\alpha-$ primed MSCs could promote tumor development via CCR1 expressed on CRC cells, which results in epithelial-mesenchymal transition via $\beta$-catenin/Slug pathway ${ }^{29}$. CCL5 is one of the C-C chemokines secreted from various cell types and interacts with CCR1, CCR3, and CCR ${ }^{31}$. The CCL5-CCR5 axis has been reported to promote tumor progression by several lines of evidence ${ }^{7,32-35}$. Karnoub et al. showed the essential role played by CCL5-CCR5 axis in breast cancer metastasis to lungs ${ }^{7}$. Velasco-Velazquez et al. showed that CCL5-CCR5 axis was preferentially activated in more malignant subtype of breast cancer, and that a CCR5 inhibitor, maraviroc, reduced the progression of CCR $5^{+}$ breast cancer cells in vitro and in vivo ${ }^{35}$. In CRC, one report showed that CCL5/CCR5 expression was upregulated in primary and metastatic $\mathrm{CRC}^{36}$, whereas another report showed that low CCR5 expression was correlated with advanced stages and reduced $\mathrm{CD}^{+}{ }^{+} \mathrm{T}$-cell infiltration $^{37}$, indicating that the role of CCR5 in CRC is still controversial. Recently, Halama et al. reported that CCL5 produced by $\mathrm{T}$ lymphocytes in CRC liver metastases has tumor-promoting effects on tumor cells and tumorassociated macrophages (TAMs), and that the CCR5 inhibitor, maraviroc, led to tumor reduction through repolarization of $\mathrm{TAMs}^{38}$. CCL3-CCR5 axis has protumorigenic effects on oral squamous cell carcinoma ${ }^{39}$, and lung metastasis ${ }^{40}$. Tanabe et al. reported that cancerassociated fibroblasts (CAFs) accumulated into tumor sites via CCL3-CCR5 axis, and that CCR5 blockage with maraviroc could suppress tumor growth in a mouse colitis-associated CRC model ${ }^{41}$. Sasaki et al. reported that CCL4-CCR5 axis could contribute to bone metastasis of breast cancer; cancer cell-derived CCL4 could induce CCR5-exrpressing fibroblasts to support tumor progression $^{42}$.

CCR5 is expressed in several types of cancer cells as well as immune cells, $\mathrm{T}$ lymphocytes, dendritic cells, leukocytes, and stromal cells ${ }^{43}$. Only a few studies have investigated the relationship between CCR5 expression and patients' prognosis ${ }^{44-47}$. In the present study, CCR5 expression was correlated with poor prognosis of CRC patients, especially those at more advanced stages (stage III/IV) (Fig. 4c). Thus, we speculate that the chemokine axis via CCR5 might be one of the critical axes for tumor progression in advanced stages.

CAFs have been known to contribute to cancer progression $^{48-50}$. Resident fibroblasts, smooth muscle cells, endothelial cells, and epithelial cells are assumed to be the sources of CAFs in the TME. Recently, some researchers reported that MSC is a potent source of CAFs. For example, Worthley et al. reported that CAFs in gastric cancer and rectal cancer of female patients who received $\mathrm{BM}$ transplants from male donors were positive for $\mathrm{Y}$ chromosome marker derived from a male BM donor, which suggests that the CAFs are derived from $\mathrm{BM}^{13}$. Using mouse models of inflammation-induced gastric dysplasia, Quante et al. showed that at least $20 \%$ of CAFs were originated from MSCs present in the $\mathrm{BM}$, and that CAFs were recruited to the tumor in a transforming growth factor- $\beta$-dependent manner together with the CXCL12-CXCR4 axis ${ }^{14}$. Jung et al. reported that CXCL16 secreted from prostate cancer facilitates conversion of MSCs into CAFs ${ }^{11}$. In the present study, we found that scattered spindle-shaped cells like fibroblasts in the xenograft co-inoculated with MSC, and that a few of them were $\alpha \mathrm{SMA}$-positive (Fig. 3c), which might delineate that some of co-inoculated MSCs could differentiate to $\alpha$ SMA-positive stromal cells like CAFs. Although MSCs have important roles in the development of TME, their mechanism of action remains to be elucidated.

As for the serum CCR5 ligands (i.e., CCL3, CCL4, and CCL5), serum levels of CCL3 and CCL4 were significantly correlated with patients' OS in diffuse large B-cell lymphoma $^{16}$. In chronic lymphocytic leukemia, serum levels of CCL3 and CCL4 were elevated ${ }^{17}$, and high CCL3 levels 
A

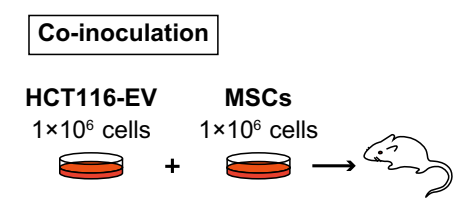

HCT116-CCR5 MSCs

$1 \times 10^{6}$ cells $\quad 1 \times 10^{6}$ cells

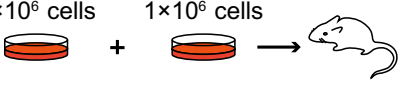

B

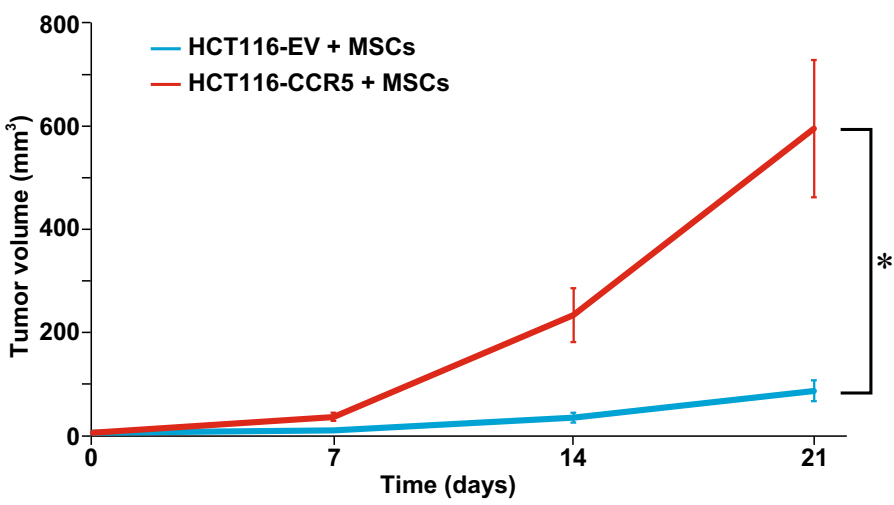

C
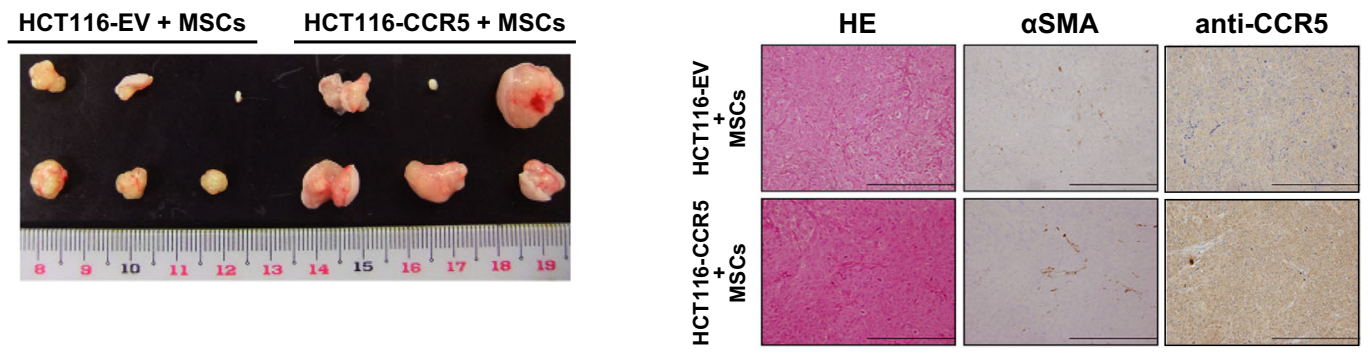

D

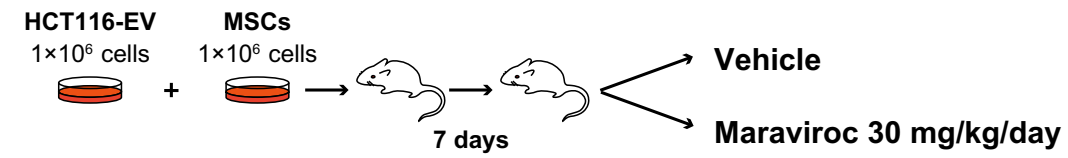

HCT116-CCR5 MSCs

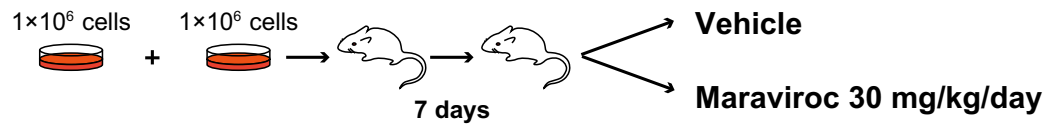

E

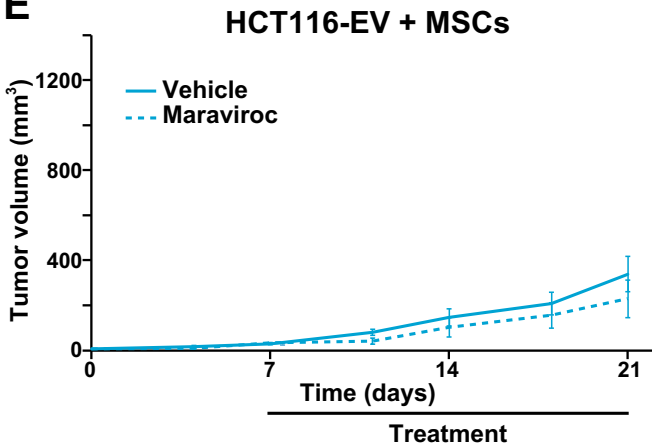

\section{HCT116-CCR5 + MSCs}

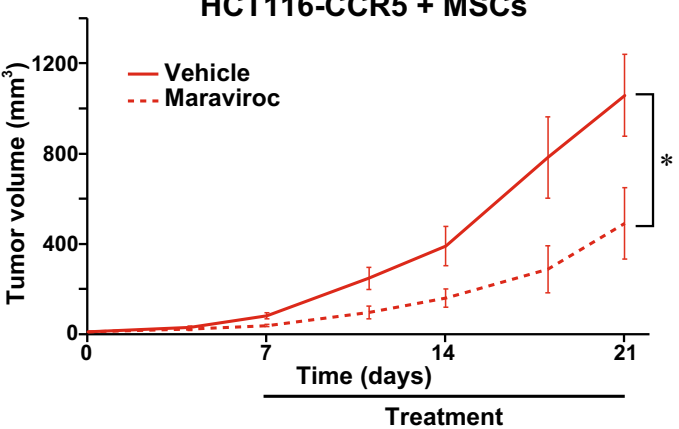

Fig. 3 Enhancement of tumor-promoting effect of mesenchymal stem cells (MSCs) by C-C chemokine receptor type 5 (CCR5) axis. a Schema of co-inoculation mice model. HCT116 transfectant cells were mixed with MSCs. b Xenograft growth curves of HCT116-EV and HCT116-CCR5 with MSCs. Mean; bar, \pm SE, $n=6$ (Student's $t$ test; ${ }^{*} P=0.01$ ). $\mathbf{c}$ Images of xenograft appearance at day 21 (left). Histological findings of xenograft (right). Hematoxylin and eosin (HE) and immunohistochemical staining for aSMA and anti-CCR5. Scale bar, $200 \mu \mathrm{m}$. d Schema of treatment schedule. e Xenograft growth curves of HCT116-EV (left) and HCT116-CCR5 (right) with MSCs. Dotted lines show treatment group with maraviroc $30 \mathrm{mg} / \mathrm{kg} /$ day, and solid lines show control group with vehicle. Means; bars, $\pm S E, n=6$ each group (Student's $t$ test, ${ }^{*} P=0.042$ )

could be a predictor of poorer prognosis ${ }^{18}$. In oral squamous cell carcinoma, high serum CCL4 levels were associated with a more advanced stage ${ }^{19}$. High serum
CCL4 levels were also reported to be associated with a poor OS in lung adenocarcinoma ${ }^{20}$. Recently, serum levels of CCL4 and CCL5 in patients with liver cirrhosis were 
A

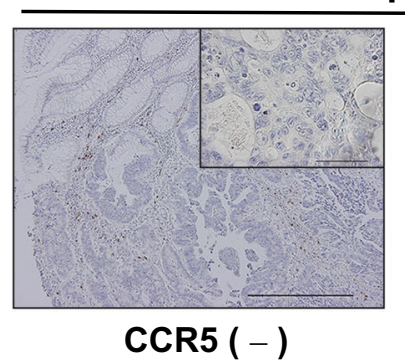

B

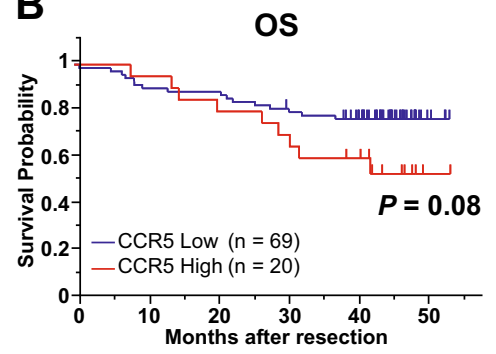

C
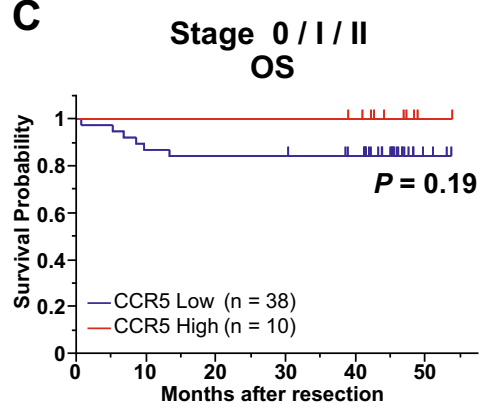

Stage III / IV OS

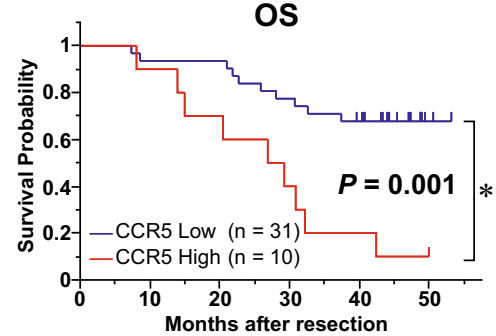

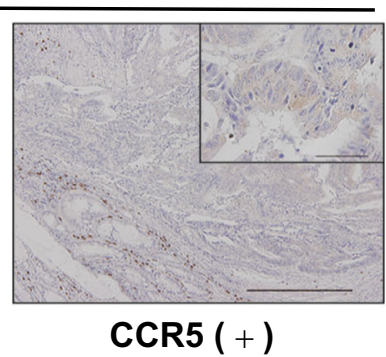

CSS

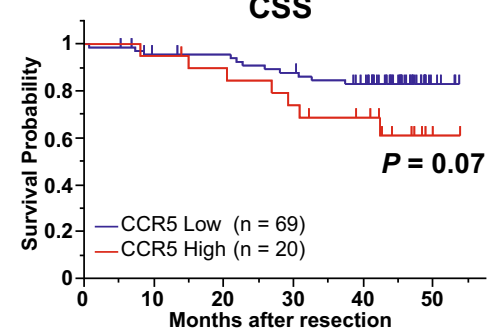

Stage $0 / I / I$

CSS

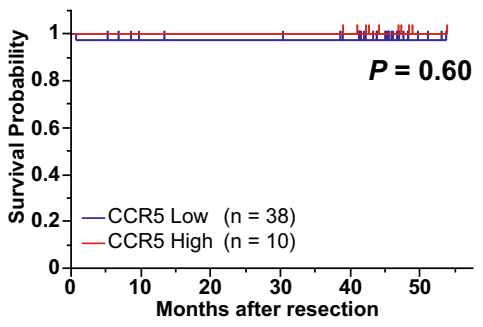

Stage III / IV CSS

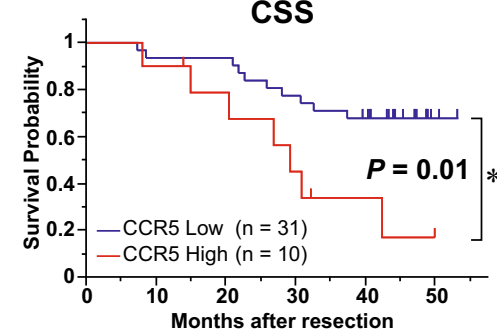

High expression

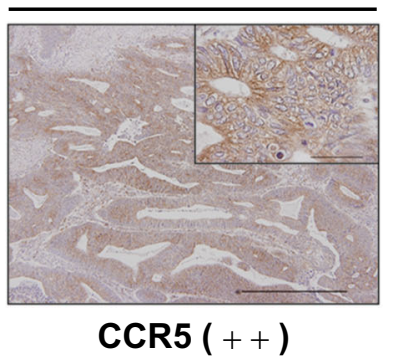

RFS

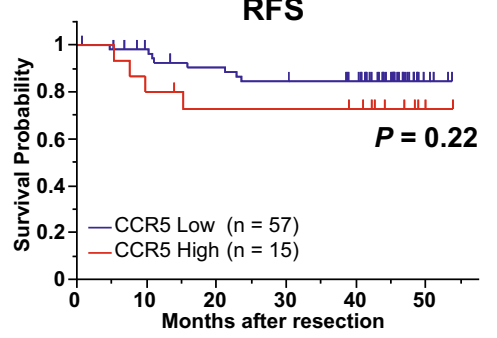

Stage $0 / I / I$

RFS

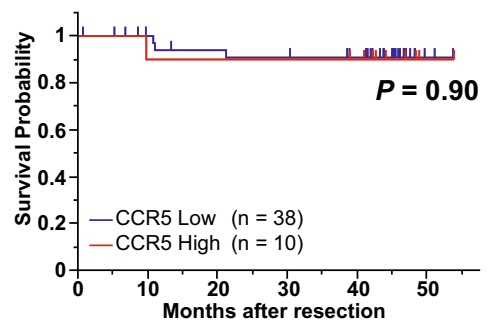

Stage III / IV

RFS

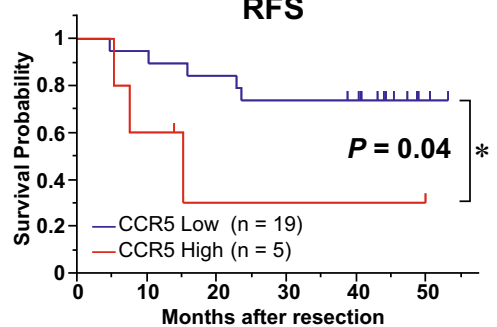

Fig. 4 Correlation of C-C chemokine receptor type 5 (CCR5) expression in primary tumor with colorectal cancer (CRC) patients' prognosis. a Immunohistochemical staining for CCR5 in primary CRC. Representative images are shown (scale bars, $500 \mu \mathrm{m}$ ). Magnified images were shown at right upper quadrant (scale bars, 50 mm). b Survival curves estimated by Kaplan-Meier method in all patients. Overall survival (OS: left), cancer-specific survival (CSS: middle), and recurrence-free survival (RFS: right) were shown. $P$ value calculated by log-rank test. c Survival curves in subgroups divided into early stages (stage 0/I/II: top) and advanced stages (stage III/IV: bottom). $P$ value calculated by log-rank test

reported to be sensitive predictors for the presence of hepatocellular carcinoma ${ }^{21}$. To our knowledge, the association of CRC with serum levels of CCL3, CCL4, and CCL5 has not been reported so far. Thus, our study is the first to evaluate this association.

The human immunodeficiency virus (HIV) utilizes CCR5 as a co-receptor with CD4 to enter target cells; therefore, the CCR5 has been heavily evaluated as an important treatment target of HIV-1 infection ${ }^{43}$. Repurposing the drugs already approved as nonanticancer drugs is an attractive strategy because of the cost, safety, and clinical validation of protocols ${ }^{51}$. In this context, CCR5 is one of the attractive targets for cancers, because it has been already used as a target for 
Table 1 Univariate analysis of patients and tumor characteristics with expression of CCR5

\begin{tabular}{|c|c|c|c|}
\hline & \multicolumn{2}{|l|}{ CCR5 } & \multirow[t]{2}{*}{$P$} \\
\hline & Negative $(n=69)$ & Positive $(n=20)$ & \\
\hline Age (mean) & 68.4 & 69.3 & 0.64 \\
\hline \multicolumn{3}{|l|}{ Sex } & 0.61 \\
\hline Male & 43 & 11 & \\
\hline Female & 26 & 9 & \\
\hline \multicolumn{3}{|l|}{ Location } & 0.80 \\
\hline Colon & 41 & 13 & \\
\hline Rectum & 28 & 7 & \\
\hline \multicolumn{3}{|c|}{ UICC-TNM stage } & 0.80 \\
\hline $0,1,11$ & 38 & 10 & \\
\hline $\mathrm{III}, \mathrm{IV}$ & 31 & 10 & \\
\hline \multicolumn{3}{|l|}{ T-factor } & 0.59 \\
\hline $\mathrm{Tis} / \mathrm{T} 1 / \mathrm{T} 2$ & 24 & 5 & \\
\hline $\mathrm{T} 3 / \mathrm{T} 4$ & 45 & 15 & \\
\hline \multicolumn{3}{|l|}{$\mathrm{N}$-factor } & 1.00 \\
\hline Negative & 43 & 12 & \\
\hline Positive & 26 & 8 & \\
\hline \multicolumn{3}{|l|}{ M-factor } & 0.76 \\
\hline Negative & 55 & 15 & \\
\hline Positive & 14 & 5 & \\
\hline
\end{tabular}

CCR5 C-C chemokine receptor type 5, UICC-TNM Union for International Cancer Control-TNM classification

inhibition of HIV entry ${ }^{52,53}$. Maraviroc is approved by $\mathrm{U}$. S. Food and Drug Administration, and commonly used for treatment of HIV infection. A new CCR5 antagonist in advanced clinical trials for treatment of HIV infection is cenicriviroc (TAK-652), which is a second-generation small-molecule CCR5 antagonist and dual chemokine receptors inhibitor for CCR2 and CCR $5^{54}$. Development of another dual chemokine-based agent (CCR5/CXCR4) is in now ongoing ${ }^{53}$. As for cancer treatments, various CCR5 antagonists, including maraviroc, vicriviroc, TAK-779, Met-CCL5, and anibamine, have been shown to have antitumor effect in preclinical mouse models ${ }^{34}$. Among them, maraviroc has been most intensively investigated in various mouse models.

In this report, we have shown that CCL3/4/5-CCR5 axis facilitates tumor progression by the interaction between MSCs and CRC cells. These results suggested that some chemokines secreted from MSCs could be important factors among the interaction between MSCs and cancer cells in the TME. Our findings that $\alpha$-CCR 5
Table 2 Patients and tumor characteristics of analyzed serum sample from another cohort of 114 patients

\begin{tabular}{|c|c|c|}
\hline Characteristics & & No. of patients \\
\hline \multicolumn{3}{|l|}{ Age, years } \\
\hline Mean \pm SD & $65 \pm 12.6$ & \\
\hline \multicolumn{3}{|l|}{ Sex } \\
\hline Male & & 56 \\
\hline Female & & 58 \\
\hline \multicolumn{3}{|l|}{ Location } \\
\hline Colon & & 79 \\
\hline Rectum & & 35 \\
\hline \multicolumn{3}{|l|}{ Histology } \\
\hline tub1/tub2 & & 98 \\
\hline Others & & 16 \\
\hline \multicolumn{3}{|l|}{ T-factor } \\
\hline $\mathrm{Tis} / \mathrm{T} 1 / \mathrm{T} 2$ & & 35 \\
\hline $\mathrm{T} 3 / \mathrm{T} 4$ & & 79 \\
\hline \multicolumn{3}{|l|}{$\mathrm{N}$-factor } \\
\hline Negative & & 76 \\
\hline Positive & & 38 \\
\hline \multicolumn{3}{|l|}{ M-factor } \\
\hline Negative & & 95 \\
\hline Positive & & 19 \\
\hline \multicolumn{3}{|l|}{ UICC-TNM stage } \\
\hline $0, I, I I$ & & 67 \\
\hline III, IV & & 47 \\
\hline \multicolumn{3}{|l|}{$\mathrm{CCL} 3, \mathrm{pg} / \mathrm{ml}$} \\
\hline$<26.0$ & & 57 \\
\hline$\geq 26.0$ & & 57 \\
\hline \multicolumn{3}{|l|}{$\mathrm{CCL} 4, \mathrm{pg} / \mathrm{ml}$} \\
\hline$<21.0$ & & 57 \\
\hline$\geq 21.0$ & & 57 \\
\hline \multicolumn{3}{|l|}{ CCL5, pg/ml } \\
\hline$<24,900$ & & 57 \\
\hline$\geq 24,900$ & & 57 \\
\hline
\end{tabular}

SD standard deviation, CCL3 C-C motif chemokine ligand 3, CCL4 C-C motif chemokine ligand 4, CCL5 C-C motif chemokine ligand 5, UICC-TNM Union for International Cancer Control-TNM classification

treatment blocked the MSC-induced tumor progression suggest that the inhibition of MSC-CRC interaction could represent an effective treatment strategy for CRC and underscore the need for clinical trials of these drugs. 
A

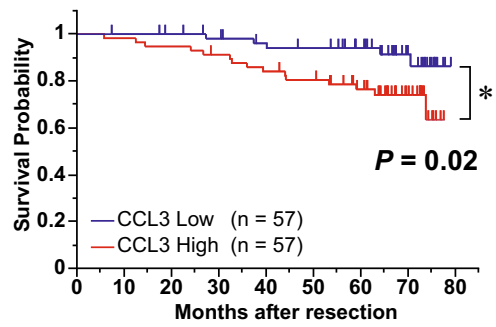

B

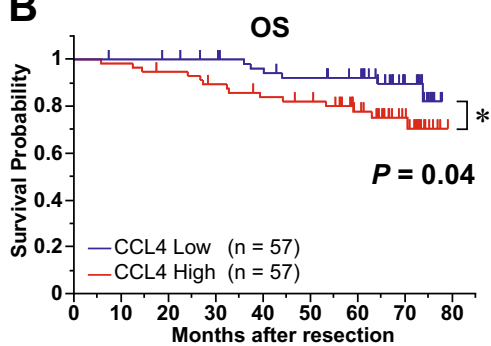

C

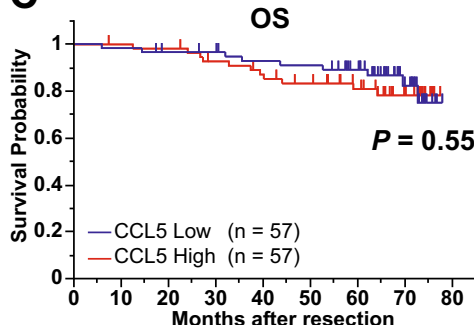

css

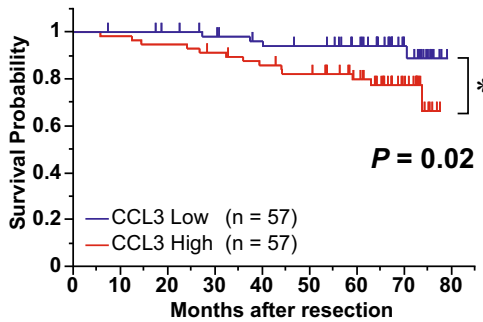

CSS
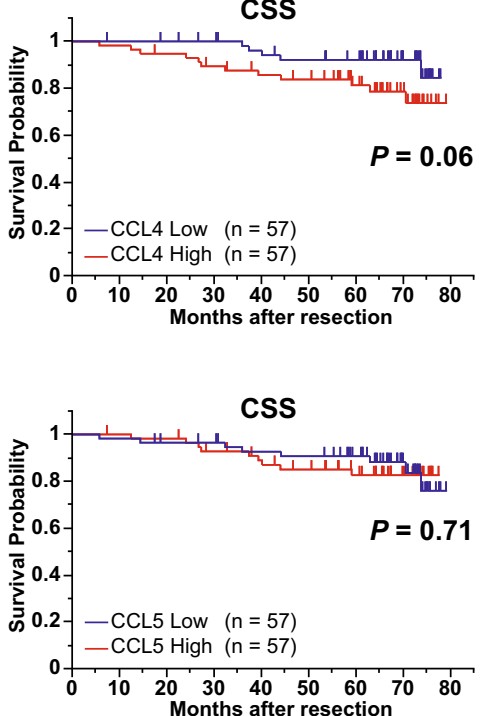

RFS

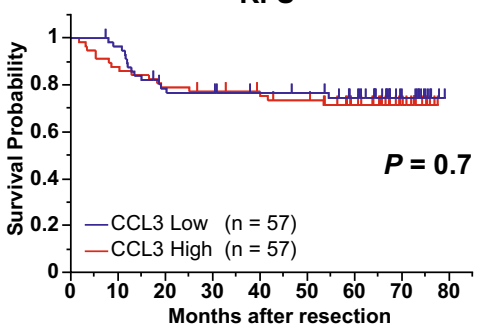

RFS

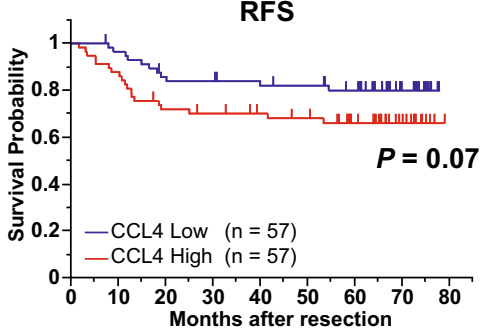

RFS

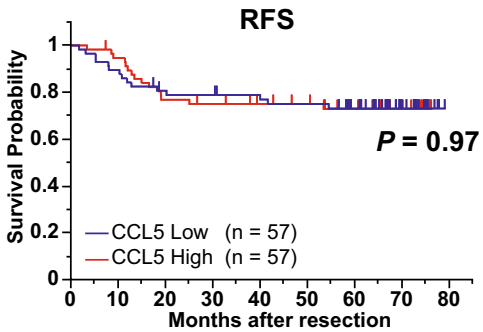

Fig. 5 Correlation of preoperative serum levels of C-C motif chemokine ligand 3 (CCL3), C-C motif chemokine ligand 4 (CCL4), and C-C motif chemokine ligand $\mathbf{5}$ (CCL5) with colorectal cancer patients' prognosis. a-c Survival curves of overall survival (OS), cancer-specific survival (CSS), and relapse-free survival (RFS) estimated by Kaplan-Meier method in CCL3 (a), CCL4 (b), and CCL5 (c). The median number of CCL3, CCL4, and CCL5 (i.e., $26.0,21.0$, and $24,900 \mathrm{pg} / \mathrm{ml}$, respectively) was used as cutoff value. $P$ value was calculated by log-rank test

\section{Materials and methods}

\section{Cell lines and reagents}

SW480, SW620, HT29, HCT116, and DLD1 human CRC cells were supplied from American Type Culture Collection and were maintained in low-glucose Dulbecco's modified Eagle's medium (DMEM; Nacalai Tesque, Kyoto, Japan) containing $10 \%$ fetal bovine serum and $1 \%$ penicillin/streptomycin mixture. Human BM-derived MSCs were supplied from Lonza (PT-2501; Basel, Switzerland) and cultured with MSCGM BulletKit (PT-3001; Lonza). We used them for experiments by passage 5 according to the manufacturer's protocol. Recombinant human CCL5/RANTES protein was obtained by $R \& D$ systems (Minneapolis, MN, USA). An antagonist of the CCR5, maraviroc, was purchased from Cayman Chemical (Ann Arbor, MI, USA).

\section{Chemokine array}

Human chemokine antibody array was obtained from RayBiotech (Norcross, GA, USA). After MSCs were cultured for $48 \mathrm{~h}$, the supernatant was collected and then analyzed by human chemokine antibody array kit (RayBiotech), according to the manufacturer's protocol. The signal intensity of each chemokine spot was measured by a LAS-3000 mini lumino image analyzer (Fjifilms, Tokyo, Japan). After substrate negative control value, relative pixel density value was calculated with the positive control as 100 .

\section{Flow cytometry}

CRC cells at subconfluency (50-70\%) were detached with $2 \mathrm{mM}$ EDTA in phosphate-buffered saline (PBS). After washes, $5 \times 10^{5} \mathrm{CRC}$ cells were incubated on ice for $30 \mathrm{~min}$ with anti-human CCR5 antibody (monoclonal mouse IgG2b clone \#45531; R\&D Systems). After washing, they were incubated with allophycocyanin-conjugated anti-mouse secondary antibodies (Cat \# 405308, BioLgend, San Diego, CA, USA) and analyzed on a BD Accuri C6 flow cytometer (BD Biosciences, San Jose, CA, USA). To evaluate CCR5 intracellular expression, cells were permalized with BD Cytofix/Cytoperm Fixation/Permeabilization 
Kit (BD Biosciences) according to the manufacturer's protocol.

\section{Retroviral transduction of HCT116 human colon cancer cell}

Human CCR5 cDNA was obtained from peripheral blood mononuclear cell of healthy donor and amplified by RT-PCR. The following primers were used, with each containing either a NotI or BamHI site. 5'-CCGGCGG CCGCGCCACCATGGATTATCAAGTGTCAAG-3' and 5'-CCGGGATCCTCACAAGCCCACAGATATTT-3'.

The obtained PCR fragment was digested with NotI and BamHI, and subcloned into retroviral vector pHIVZsGreen (from Hisamori S, Kyoto University). The resulting vector was confirmed by sequencing to coincident with the published data (GenBank Accession No. NM_000579). Using lentiviral packaging plasmid psPAX2 and VSV-G envelope expressing plasmid pMD2.G, HCT116 CRC cells were transfected pHIV-CCR5-IRESZsGreen with produced lentivirus. After initial transfection, the high expressed ZsGreen cells were isolated using BD FACSAria II cell sorter (BD Biosciences).

\section{qRT-PCR analyses}

Total RNA was extracted and reverse transcription was performed with RevaTra Ace (TYOBO, Osaka, Japan) according to the manufacturer's protocol. The synthesized cDNA was quantified with StepOnePlus Real-Time PCR system (Thermo Fisher Scientific, Waltham, MA, USA) and THUNDERBIRD SYBR qPCR Mix (TOYOBO). The flowing primers were used: CCR5, 5'-CACAGG GCTGTGAGGCTTAT- ${ }^{\prime}$ ' and $5^{\prime}$-TCACCTGCATAGCT TGGTCC-3'; ACTb, 5'-GCAAAGACCTGTACGCCAA C-3' and 5'-ACATCTGCTGGAAGGTGGAC-3'.

\section{Western blot analysis}

Cells were lysed with SDS sample buffer $(70 \mathrm{mM}$ Tris$\mathrm{HCl}, 3 \% \mathrm{SDS}$, and 10\% glycerol) with inhibitor cocktails of protease and phosphatase. Primary antibodies were rabbit monoclonal anti-phospho-p44/42 kinase (Thr202/Tyr204: Cell Signaling Technology, Danvers, MA, USA), anti-p44/42 kinase (Cell Signaling Technology), rabbit monoclonal anti-phospho-Akt (Ser473: Cell Signaling Technology), rabbit monoclonal anti-Akt (Cell Signaling Technology), rabbit polyclonal antiphospho-p70 S6 kinase (Thr389: Cell Signaling Technology), rabbit polyclonal anti-p70 S6 kinase (Cell Signaling Technology), and mouse monoclonal anti- $\beta$ actin-peroxidase (Sigma-Aldrich, St. Louis, MO, USA). For stimulation experiments, cells were starved for $24 \mathrm{~h}$ with serum-free DMEM and then stimulated with 100 $\mathrm{ng} / \mathrm{ml}$ of CCL5. Cell lysates were obtained after the indicated times stimulation and subjected to SDSpolyacrylamide gel electrophoresis, immunoblotted with the primary antibodies followed by horseradish peroxidase-conjugated secondary antibodies, and then analyzed by a lumino image analyzer.

\section{Cell proliferation assay}

Cell proliferation was assayed with Cell Counting Kit-8 (Dojin, Kumamoto, Japan) according to the manufacturer's protocol. Cells were cultured at a density of 2000 cells/well of 96-well plate in serum-free media with or without chemokine ligand CCL5. Each sample were analyzed absorbance at day 0,3 , and 6 , and calculated relative rate with day 0 value as 1 .

\section{Chemotaxis assay}

Migration assay was assayed in 24-well Transwell cell culture chambers $(8 \mu \mathrm{m}$-pore membrane) (Corning, NY, USA). Membrane were precoated with $5 \mu \mathrm{g}$ of fibronectin in a volume of $50 \mu \mathrm{l}$ on the lower surface, dried, and washed before use. After $24 \mathrm{~h}$ starvation with serum-free DMEM, HCT116-EV or CCR5-OE cells $\left(2 \times 10^{4}\right.$ cells/ well) were added to the upper chamber and serum-free media with indicated ligand concentration was added to the lower chamber. After $6 \mathrm{~h}$ incubation, cells attached on the lower surface of the membrane were counted in at least five different fields (original magnification $\times 200$ ).

\section{Animal tumor model}

Eight- to 11-week-old female KSN/slc nude mice (Japan SLC, Hamamatsu, Japan) were bred under specific pathogen-free conditions. Protocols of animal assay were approved by the Animal Experiment Committee of the University of Kyoto. For assessment of the role of coexisted MSC, the mice were divided into two group, and $1 \times$ $10^{6} \mathrm{CRC}$ cells alone or both $1 \times 10^{6} \mathrm{CRC}$ cells and $1 \times 10^{6}$ MSCs in $100 \mu \mathrm{l}$ PBS were subcutaneously injected into the flanks of each mouse. To examine maraviroc inhibitory effect on interaction between CRC and MSCs, HCT116EV and HCT116-CCR5 cells were co-inoculated with MSCs in the same manner and the mice were randomized in control group (vehicle, $100 \mu \mathrm{l}$ PBS with 5\% dimethyl sulfoxide, intraperitoneal (i.p.)) and treatment group (maraviroc $30 \mathrm{mg} / \mathrm{kg}$, i.p.). Treatment was started at day 7 after cell inoculation and continued for 14 days. Tumor volumes were calculated using the formula (length $x$ width $\left.^{2}\right) \times 0.5$.

\section{Immunohistochemistry}

Formalin-fixed, paraffin-embedded sections were stained with anti-human CCR5 antibody (anti-human CCR5 antibody: monoclonal mouse IgG2b clone \# 45523, dilution 1:50) (R\&D) by the avidin-biotin immunoperoxidase method. Antigen retrieval was conducted in citrate buffer ( $\mathrm{pH}$ : 6.0) at sub-boiling temperature for $10 \mathrm{~min}$. The primary antibodies were applied and incubated over night at $4{ }^{\circ} \mathrm{C}$. For primary CRC tissue, the expression of 
CCR5 was classified into three groups based on the expression intensity: -, absent; + , positive (almost cytoplasmic staining); ++ , strong positive (membranous staining) and was defined to be high expression if the tumors possessed strong positively stained $(++)$ cells and to be low expression if positively stained or absent. The slides were evaluated without prior knowledge of other data.

\section{Enzyme-linked immunosorbent assay}

Serum protein levels of CCL3, CCL4, and CCL5 were measured with Human CCL3, CCL4, and CCL5 DuoSet ELISA (R\&D), according to the manufacturer's protocol. The serum protein levels of CCL3, CCL4, and CCL5 were divided into high group and low group. Median vale was used as cutoff value.

\section{Patients and clinicopathological data}

A total 89 of resected CRC samples were collected at Kyoto University Hospital in 2008. For the analysis of serum CCL3, CCL4, and CCL5 levels, preoperative serum samples were collected from 114 CRC patients between 2011 and 2014. These study protocols were approved by the Institutional Review Board of Kyoto University, and the patients provided their consents for data analysis.

\section{Statistical analysis}

Analyzed values were expressed as means \pm standard deviation in in vitro experiments and means \pm standard error in in vivo experiments. Categorical data were determined with Fisher's exact test. Continuous variables were determined with Student's $t$ test. The log-rank test was used for analysis of OS, CSS, and RFS. All analyses were two-sided, and $P$ value $<0.05$ was considered as statistically significant. Statistical analyses were performed using JMP Pro software, version 14.0.0 (SAS Institute Inc, Cary, NC, USA).

\section{Acknowledgements}

This work was supported by grants from the Ministry of Education, Culture Sports, Science and Technology of Japan, from Project Mirai Cancer Research, and from The NOVARTIS Foundation (Japan) for the Promotion of Science (to K.K.).

\section{Conflict of interest}

The authors declare that they have no conflict of interest.

\section{Publisher's note}

Springer Nature remains neutral with regard to jurisdictional claims in published maps and institutional affiliations.

Supplementary Information accompanies this paper at (https://doi.org/ 10.1038/s41419-019-1508-2).

Received: 6 December 2018 Revised: 21 February 2019 Accepted: 5 March 2019
Published online: 19 March 2019

\section{References}

1. Ferlay, J. et al. Cancer incidence and mortality worldwide: sources, methods and major patterns in GLOBOCAN 2012. Int. J. Cancer 136, E359-E386 (2015).

2. Siegel, R. et al. Cancer treatment and survivorship statistics, 2012. CA Cancer J. Clin. 62, 220-241 (2012)

3. Joyce, A. \& Pollard, J. W. Microenvironmental regulation of metastasis. Nat. Rev. Cancer 9, 239-252 (2009).

4. Friedenstein, A. J., Chailakhjan, R. K. \& Lalykina, K. S. The development of fibroblast colonies in monolayer cultures of guinea-pig bone marrow and spleen cells. Cell Tissue Kinet. 3, 393-403 (1970).

5. Shi, Y., Du, L., Lin, L. \& Wang, Y. Tumour-associated mesenchymal stem/stromal cells: emerging therapeutic targets. Nat. Rev. Drug Discov. 16, 35-52 (2017).

6. Dvorak, H. F. Tumors: wounds that do not heal. Similarities between tumor stroma generation and wound healing. N. Engl. J. Med. 315, 1650-1659 (1986).

7. Karnoub, A. E. et al. Mesenchymal stem cells within tumour stroma promote breast cancer metastasis. Nature 449, 557-563 (2007).

8. Torsvik, A. \& Bjerkvig, R. Mesencymal stem cell signaling in cancer progression. Cancer Treat. Rev. 39, 180-188 (2013).

9. Cuiffo, B. G. \& Karnoub, A. E. Mesenchymal stem cells in tumor development. Cell Adh. Migr. 6, 220-230 (2012).

10. Chaturvedi, P. et al. Hypoxia-inducible factor-dependent breast cancermesenchymal stem cell bidirectional signaling promotes metastasis. J. Clin. Invest. 123, 189-205 (2013).

11. Jung, Y. et al. Recruitment of mesenchymal stem cells into prostate tumours promotes metastasis. Nat. Commun. 4, 1795 (2013).

12. Prantl, L. et al. Adipose tissue-derived stem cells promote prostate tumor growth. Prostate 70, 1709-1715 (2010).

13. Worthley, D. L. et al. Human gastrointestinal neoplasia-associated myofibroblasts can develop from bone marrow-derived cells following allogeneic stem cell transplantation. Stem Cells 27, 1463-1468 (2009).

14. Quante, $M$. et al. Bone marrow-derived myofibroblasts contribute to the mesenchymal stem cell niche and promote tumor growth. Cancer Cell 19, 257-272 (2011).

15. Huang, F. et al. Gastric cancer-derived MSC-secreted PDGF-DD promotes gastric cancer progression. J. Cancer Res. Clin. Oncol. 140, 1835-1848 (2014).

16. Takahashi, K. et al. CCL3 and CCL4 are biomarkers for B cell receptor pathway activation and prognostic serum markers in diffuse large B cell lymphoma. Br. J. Haematol. 171, 726-735 (2015).

17. Ponader, S. et al. The Bruton tyrosine kinase inhibitor PCl-32765 thwarts chronic lymphocytic leukemia cell survival and tissue homing in vitro and in vivo. Blood 119, 11824-1189 (2012).

18. Sivina, M. et al. CCL3 (MIP-1a) plasma levels and the risk for disease progression in chronic lymphocytic leukemia. Blood 117, 1662-1669 (2011).

19. Trellakis, S. et al. Polymorphonuclear granulocytes in human head and neck cancer: enhanced inflammatory activity, modulation by cancer cells and expansion in advanced disease. Int. J. Cancer 129, 2183-2193 (2011).

20. Li, L. et al. High levels of CCL2 or CCL 4 in the tumor microenvironment predict unfavorable survival in lung adenocarcinoma. Thorac. Cancer 9, 775-784 (2018).

21. Sadeghi, M. et al. Serum levels of chemokines CCL4 and CCL5 in cirrhotic patients indicate the presence of hepatocellular carcinoma. Br. J. Cancer 113, 756-762 (2015)

22. Wei, X. et al. Mesencymal stem cells: a new trend for cell therapy. Acta Pharmacol. Sin. 34, 747-754 (2013).

23. Casiraghi, F., Remuzzi, G., Abbate, M. \& Perico, N. Multipotent mesenchyamal stromal cell therapy and risk of malignancies. Stem Cell Rev. 9, 65-79 (2013).

24. Barkholt, L. et al. Risk of tumorigenicity in mesenchymal stromal cell-based therapies-bridging scientific observations and regulatory viewpoints. Cytotherapy 15, 753-759 (2013).

25. Medeiros Tavares Marques, J. C. et al. Identification of new genes associated to senescent and tumorigenic phenotypes in mesenchymal stem cells. Sci. Rep. 7, 17837 (2017).

26. Shinagawa, K. et al. Mesenchymal stem cells enhance growth and metastasis of colon cancer. Int. J. Cancer 127, 2323-2333 (2010).

27. Tsai, K. S. et al. Mesenchymal stem cells promote formation of colorectal tumors in mice. Gastroenterology 141, 1046-1056 (2011). 
28. De Boeck, A. et al. Bone marrow-derived mesenchymal stem cells promote colorectal cancer progression through paracrine neuregulin 1/HER3 signalling. Gut 62, 550-560 (2013).

29. Chen, K. et al. Human MSCs promotes colorectal cancer epithelialmesenchymal transition and progression via CCL5/beta-catenin/Slug pathway. Cell Death Dis. 8, e2819 (2017).

30. Zhang, X. et al. Human colorectal cancer-derived mesenchymal stem cells promote colorectal cancer progression through IL-6/JAK2/STAT3 signaling. Cell Death Dis. 9, 25 (2018).

31. Lin, S. J. et al. Low-molecular-mass secretome profiling identifies C-C motif chemokine 5 as a potential plasma biomarker and therapeutic target for nasopharyngeal carcinoma. J. Proteomics 94, 186-201 (2013).

32. Murooka, T. T., Rahbar, R. \& Fish, E. N. CCL5 promotes proliferation of MCF-7 cells through mTOR-dependent mRNA translation. Biochem. Biophys. Res. Commun. 387, 381-386 (2009).

33. Wang, S. W. et al. CCL5 and CCR5 interaction promotes cell motility in human osteosarcoma. PLoS ONE 7, e35101 (2012).

34. Aldinucci, D. \& Casagrande, N. Inhibition of the CCL5/CCR5 axis against the progression of gastric cancer. Int. J. Mol. Sci. 19, 1477-1492 (2018).

35. Velasco-Velazquez, M. et al. CCR5 antagonist blocks metastasis of basal breast cancer cells. Cancer Res. 72, 3839-3850 (2012).

36. Cambien, B. et al. CCL5 neutralization restricts cancer growth and potentiates the targeting of PDGFRbeta in colorectal carcinoma. PLOS ONE 6, e28842 (2011).

37. Zimmermann, T. et al. Low expression of chemokine receptor CCR5 in human colorectal cancer correlates with lymphatic dissemination and reduced CD8 + T-cell infiltration. Int. J. Colorectal Dis. 25, 417-424 (2010).

38. Halama, N. et al. Tumoral immune cell exploitation in colorectal cancer metastases can be targeted effectively by anti-CCR5 therapy in cancer patients. Cancer Cell 29, 587-601 (2016).

39. da Silva, J. M. et al. Relevance of CCL3/CCR5 axis in oral carcinogenesis. Oncotarget 8, 51024-51036 (2017).

40. Wu, Y., Li, Y. Y., Matsushima, K., Baba, T. \& Mukaida, N. CCL3-CCR5 axis regulates intratumoral accumulation of leukocytes and fibroblasts and promotes angiogenesis in murine lung metastasis process. J. Immunol. 181, 6384-6393 (2008).
41. Tanabe, Y., Sasaki, S., Mukaida, N. \& Baba, T. Blockade of the chemokine receptor, CCR5, reduces the growth of orthotopically injected colon cancer cells via limiting cancerassociated fibroblast accumulation. Oncotarget 7, 48335-48345 (2016).

42. Sasaki, S. et al. Essential roles of the interaction between cancer cell-derived chemokine, CCL4, and intra-bone CCR5-expressing fibroblasts in breast cancer bone metastasis. Cancer Lett. 378, 23-32 (2016).

43. Woollard, S. M. \& Kanmogne, G. D. Maraviroc: a review of its use in HIV infection and beyond. Drug Des. Devel. Ther. 9, 5447-5468 (2015).

44. Borczuk, A. C. et al. Lung adenocarcinoma invasion in TGFbetaRll-deficient cells is mediated by CCL5/RANTES. Oncogene 27, 557-564 (2008).

45. Sugasawa, $H$. et al. Prognostic significance of expression of CCL5/ RANTES receptors in patients with gastric cancer. J. Surg. Oncol. 97, 445-450 (2008).

46. Luboshits, G. et al. Elevated expression of the CC chemokine regulated on activation, normal $T$ cell expressed and secreted (RANTES) in advanced breast carcinoma. Cancer Res. 59, 4681-4687 (1999).

47. Jiao, $X$. et al. CCR5 governs DNA damage repair and breast cancer stem cell expansion. Cancer Res. 78, 1657-1671 (2018).

48. Kalluri, R. \& Zeisberg, M. Fibroblasts in cancer. Nat. Rev. Cancer 6, 392-401 (2006).

49. Tsujino, T. et al. Stromal myofibroblasts predict disease recurrence for colorectal cancer. Clin. Cancer Res. 13, 2082-2090 (2007).

50. Tommelein, J. et al. Cancer-associated fibroblasts connect metastasispromoting communication in colorectal cancer. Front. Oncol. 5, 63-73 (2015).

51. Bertolini, F., Sukhatme, V. P. \& Bouche, G. Drug repurposing in oncology-patient and health systems opportunities. Nat. Rev. Clin. Oncol. 12, 732-742 (2015).

52. Lederman, M. M., Penn-Nicholson, A., Cho, M. \& Mosier, D. Biology of CCR5 and its role in HIV infection and treatment. JAMA 296, 815-826 (2006).

53. Kim, M. B. et al. CCR5 receptor antagonists in preclinical to phase II clinical development for treatment of HIV. Expert Opin. Investig. Drugs 25, 1377-1392 (2016).

54. Thompson, M. et al. A 48-week randomized phase $2 \mathrm{~b}$ study evaluating cenicriviroc versus efavirenz in treatment-naive HIV-infected adults with C-C chemokine receptor type 5-tropic virus. AIDS 30, 869-878 (2016). 